\title{
Stabilization of the Serum Lithium Concentration by Regulation of Sodium Chloride Intake: Case Report
}

\author{
Takashi Tomita, ${ }^{*, a}{ }^{\dagger}$ Hidekazu Goto, ${ }^{a}$ Kenji Sumiya, ${ }^{b}$ Tadashi Yoshida, ${ }^{c}$ \\ Katsuya Tanaka, ${ }^{d}$ and Yukinao Kohda ${ }^{a, e}$ \\ ${ }^{a}$ Department of Pharmacy, Hospital Bando; 411 Kutsukake, Bando, Ibaraki 306-0515, Japan: baculty of Pharmacy, \\ Iwaki Meisei University; 5-5-1 Chuodai Iino, Iwaki, Fukushima 970-8551, Japan; 'Department of Internal Medicine, \\ Hospital Bando; 411 Kutsukake, Bando, Ibaraki 306-0515, Japan: 'Department of Psychiatry, Hospital Bando; \\ 411 Kutsukake, Bando, Ibaraki 306-0515, Japan: and ${ }^{e}$ Faculty of Health Sciences, Tsukuba \\ International University; 6-20-1 Manabe, Tsuchiura, Ibaraki 300-0051, Japan.
}

(Received September 11, 2015; Accepted October 25, 2015)

\begin{abstract}
To avoid fluctuation of the serum lithium concentration $\left(\mathrm{C}_{\mathrm{Li}}\right)$, sodium chloride $(\mathrm{NaCl})$ intake was regulated in oral alimentation. A 62-year-old woman was hospitalized and orally administered $400 \mathrm{mg}$ of lithium carbonate a day to treat her mania. Her $\mathrm{C}_{\mathrm{Li}}$ was found to be $0.75-0.81 \mathrm{mEq} / \mathrm{L}$. Vomiting made it difficult for the patient to ingest meals orally, and therefore parenteral nutrition with additional oral intake of protein-fortified food was initiated. On day 22 , parenteral nutrition was switched to oral alimentation to enable oral intake of food. The total $\mathrm{NaCl}$ equivalent amount was decreased to $1.2 \mathrm{~g} / \mathrm{d}$, and the $\mathrm{C}_{\mathrm{Li}}$ increased to $1.15 \mathrm{mEq} / \mathrm{L}$ on day 26 . Oral alimentation with semi-solid food blended in a mixer was immediately initiated. Although the total $\mathrm{NaCl}$ equivalent amount was increased to $4.5-5.0 \mathrm{~g} / \mathrm{d}$, her $\mathrm{C}_{\mathrm{Li}}$ remained high at $1.14-1.17 \mathrm{mEq} / \mathrm{L}$ on days 33 and 49 , respectively. We investigated oral administration of $\mathrm{NaCl}(1.8 \mathrm{~g} / \mathrm{d})$ on day 52. The total $\mathrm{NaCl}$ equivalent amount was increased to $6.3-6.8 \mathrm{~g} / \mathrm{d}$, and the $\mathrm{C}_{\mathrm{Li}}$ decreased to $1.08-0.97 \mathrm{mEq} / \mathrm{L}$ on days 63 and 104, respectively. After the start of the orally administered $\mathrm{NaCl}$, her diet was changed to a completely blended diet on day 125 . The total $\mathrm{NaCl}$ equivalent amount was increased to $9.0-14.5 \mathrm{~g} / \mathrm{d}$, and the $\mathrm{C}_{\mathrm{Li}}$ decreased to 0.53 $\mathrm{mEq} / \mathrm{L}$ on day 152; therefore, the oral administration of $\mathrm{NaCl}$ was discontinued on day 166 . The $\mathrm{C}_{\mathrm{Li}}$ was found to be $0.70-0.85 \mathrm{mEq} / \mathrm{L}$ on days 176 and 220 .
\end{abstract}

Key words_- lithium level stabilization; drug level monitoring; sodium chloride intake; parenteral nutrition; oral alimentation

\section{INTRODUCTION}

Lithium carbonate is a drug widely used for treating mania. The serum lithium concentration must be monitored during administration of this drug in order to prevent poisoning or overdose. It is administered carefully only to those patients are at risk of retaining lithium in the body, and it is contraindicated for patients who are likely to retain lithium in the body, such as those with sodium chloride restrictions. ${ }^{1)}$

We report the case of a hospitalized patient who was under nutritional management focused on parenteral nutrition and was switched to oral alimentation in order to enable oral ingestion of meals. This led to changes in the serum lithium concentration owing to changes in the total amount of sodium chloride. We observed that modifying the patient's sodium intake

Prcsent address: ${ }^{\dagger}$ Department of Clinical Pharmaceutics and Pharmacy Practice, School of Pharmacy, Iwate Medical University

*e-mail: tatomita@iwate-med.ac.jp allowed stabilization of the serum lithium concentration.

\section{CASE}

A 62-year-old woman was hospitalized and orally administered $400 \mathrm{mg}$ lithium carbonate a day to treat her mania (only underlying disease) during this study period. Her serum lithium concentration was found to be $0.75-0.81 \mathrm{mEq} / \mathrm{L}$. Vomiting made it difficult for the patient to orally ingest her meals, and therefore nutritional management (total sodium chloride equivalent amount: $3.3-4.1 \mathrm{~g} / \mathrm{d}$; amount of energy administered: $910-1610 \mathrm{kcal} / \mathrm{d}$ ) focused on parenteral nutrition (Fulcaliq ${ }^{\circledR}$ infusion: $903 \mathrm{~mL} / \mathrm{d}$ ) with additional oral intake of protein-fortified food (EPUrich: 1-3 packs) was initiated. Her serum sodium concentration was maintained with the normal range of $139-141 \mathrm{mEq} / \mathrm{L}$ (Fig. 1) .

On day 22, we attempted to switch her from parenteral nutrition to oral alimentation in order to enable oral intake of food. Discontinuing parenteral nutri- 
Parenteral

\begin{tabular}{|l|l|}
\hline Semi-solid blended diet & Completely blended diet \\
\hline
\end{tabular}
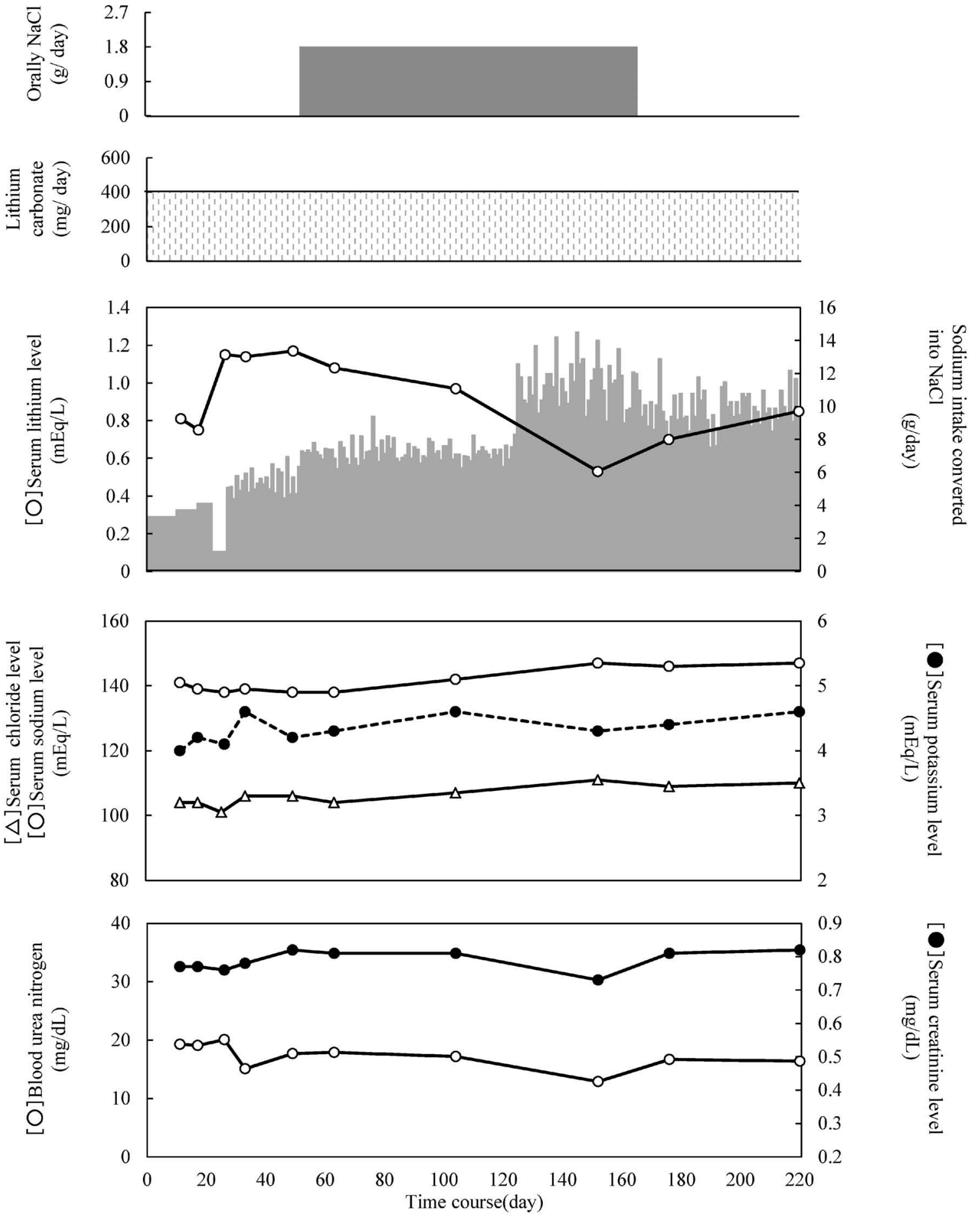

Fig. 1. Changes in the Serum Lithium Concentration, Laboratory Data, and Nutritional Intake of the Patient

tion led to a decrease in the total sodium chloride equivalent amount by approximately $3.0 \mathrm{~g} / \mathrm{d}$ compared to baseline, and the patient's sodium intake decreased to $1.2 \mathrm{~g} / \mathrm{d}$ (only through oral intake of pro- tein-fortified food) in terms of the total sodium chloride equivalent amount. Since the decrease in sodium chloride intake led to elevated serum lithium concentration, we measured her serum lithium concentration 
on day 4 after discontinuation of parenteral nutrition. On day 26, we noted that the serum lithium concentration had increased to $1.15 \mathrm{mEq} / \mathrm{L}$. No adverse events appeared, and her serum sodium concentration was $138 \mathrm{mEq} / \mathrm{L}$. On day 27, oral alimentation with semi-solid food blended in a mixer was immediately initiated. Although we were able to ensure that the total sodium chloride equivalent amount $(4.5-5.0 \mathrm{~g} / \mathrm{d})$ was more than that administered while she was on parenteral nutrition, her serum lithium concentration remained high at 1.14 and $1.17 \mathrm{mEq} / \mathrm{L}$ on days 33 and 49 ( 6 and $22 \mathrm{~d}$ after the semi-solid blended diet), respectively. Her serum sodium concentration was $138-139 \mathrm{mEq} / \mathrm{L}$.

On day 52, we attempted to reduce the lithium carbonate dosage in order to decrease the serum lithium concentration; however, taking into consideration the reported case of lithium poisoning that was treated by drip saline, ${ }^{2)}$ we investigated administration of sodium chloride. The target amount of sodium intake in the present case was less than $7.0 \mathrm{~g} / \mathrm{d}$ in terms of the total sodium chloride equivalent amount, but treatment by oral administration of sodium chloride (1.8 $\mathrm{g} / \mathrm{d}$, three capsules) was attempted because the semisolid blended diet failed to provide adequate sodium and the patient had to ingest the diet orally. The total sodium chloride equivalent amount was increased to $6.3-6.8 \mathrm{~g} / \mathrm{d}$ with orally administered sodium chloride, and the serum lithium concentration decreased to 1.08 and $0.97 \mathrm{mEq} / \mathrm{L}$ on days 63 and 104 (36 and $77 \mathrm{~d}$ after the semi-solid blended diet, 11 and $52 \mathrm{~d}$ after the orally sodium chloride), respectively.

On day 125 ( $73 \mathrm{~d}$ after the orally sodium chloride), her diet was changed from a semi-solid blended diet to a completely blended diet. The total sodium chloride equivalent amount was increased to $9.0-14.5 \mathrm{~g} / \mathrm{d}$, and the serum sodium concentration increased to 147 $\mathrm{mEq} / \mathrm{L}$ on day $152(27 \mathrm{~d}$ after the completely blended diet, $100 \mathrm{~d}$ after the orally sodium chloride), while the serum lithium concentration decreased to 0.53 $\mathrm{mEq} / \mathrm{L}$; therefore, oral administration of sodium chloride was discontinued. The serum lithium concentration increased to 0.70 and $0.85 \mathrm{mEq} / \mathrm{L}$ on days 176 and 220 (51 and $95 \mathrm{~d}$ after the completely blended diet, 10 and $54 \mathrm{~d}$ after the discontinuation of orally sodium chloride), respectively.

The patient's clinical laboratory values during the reporting period in some instances did not temporarily conform to the set benchmarks in terms of the elec- trolytes, but were within the range (serum potassium concentration: $4.0-4.6 \mathrm{mEq} / \mathrm{L}$; serum chloride concentration: $104-111 \mathrm{mEq} / \mathrm{L}$; serum sodium concentration: $138-147 \mathrm{mEq} / \mathrm{L}$ ). The renal function showed a mild to moderate decrease (serum creatinine levels: $0.73-0.82 \mathrm{mg} / \mathrm{dL}$; estimated glomerular filtration rate: $54.5-61.9 \mathrm{~mL} / \mathrm{min} / 1.73 \mathrm{~m}^{2}$ and $37.2-42.2 \mathrm{~mL} /$ min without correction for body surface area; estimated creatinine clearance: $43.8-49.2 \mathrm{~mL} / \mathrm{dL}$ calculated by Cockcroft-Gault (CG) formula and $59.8 \mathrm{~mL} /$ min calculated by GC formula using corrected serum creatinine $(0.6 \mathrm{mg} / \mathrm{dL})$; blood urea nitrogen levels: $12.9-19.3 \mathrm{mg} / \mathrm{dL}$ ). The patient's body weight was approximately $39.5 \mathrm{~kg}$ and her body-mass index (BMI) was 22.5 during this study period of 6 months.

The patient has regular consultations with her doctor. A symptom of mania also remained stable during this study period. The Young Mania Rating Scale (YMRS) is a diagnostic questionnaire commonly used to evaluate manic symptoms in patients with mania. Three of the eleven individual YMRS items were observed: appearance, irritability, and sleep. The exacerbation of symptoms was not observed.

\section{DISCUSSION}

Lithium carbonate is one of the drugs of interest in clinical settings for the treatment of decreased renal function. The dosage of lithium carbonate in the present case was $400 \mathrm{mg} / \mathrm{d}$, which was below the 600 $\mathrm{mg} / \mathrm{d}$ dosage that is considered safe for patients with renal failure and decreased kidney lithium excretion function; however, the upper limit for serum lithium concentration was set at $0.8 \mathrm{mEq} / \mathrm{L}$ to prevent lithium poisoning caused by an increase in the amount stored in the body. ${ }^{3)}$ In light of the patient's estimated creatinine clearance and estimated glomerular filtration rate, fluctuations in lithium clearance owing to mild to moderate decreased renal function may have been one of the causes for the change in the patient's serum lithium concentration.

Another possible cause for changes in serum lithium concentration includes dehydration. However, her passage of urine (mean, 4.4 times/d) and stool (mean, 0.7 times/d) was common, and there was no onset of diarrhea. Her body weight remained stable, and she showed no sign of sweating. These findings and observations suggest that the changes in serum lithium concentration were not caused by fluctuations in renal function that may have resulted from de- 
hydration.

With regards to the relationship between concomitantly used drugs and elevated serum lithium concentration in the present case, the patient was not administered any drugs, that would have affected the serum lithium concentration, and therefore, the changes in serum lithium concentration may not have been caused by any concomitantly used drugs.

The Dietary Reference Intake for sodium in Japanese people ${ }^{4)}$ states that the estimated mean amount required for women, aged 50-69 years, is 1.5 $\mathrm{g} / \mathrm{d}$ in terms of the sodium chloride equivalent, with the target being less than $7.0 \mathrm{~g} / \mathrm{d}$ in terms of the sodium chloride equivalent. The amount of sodium ingested in the present case was approximately $1.2 \mathrm{~g} / \mathrm{d}$ of the total sodium chloride equivalent, which is lower than the estimated mean amount that is required, but her serum sodium concentration did not vary significantly and remained within the normal range. Lithium ions are freely filtered through the glomerulus and reabsorbed in the proximal tubule in the same proportion of sodium and water. There could be some reabsorption of lithium in the loop of Henle on some extreme condition. However, there is almost no reabsorption of lithium in the distal tubule. Lithium clearance and the difference between lithium and sodium clearance are, therefore, indicators of sodium reabsorption in the proximal and distal tubules. ${ }^{5)} \mathrm{Ow}-$ ing to the decrease in the total sodium chloride equivalent amount, her serum lithium concentration rose to as high as $1.17 \mathrm{mEq} / \mathrm{L}$, but was controlled at less than $1.50 \mathrm{mEq} / \mathrm{L}$, which is the concentration at which side effects appear. We carefully monitored her total sodium chloride equivalent amount simultaneously with her serum lithium concentration because we had previously experienced a case ${ }^{6}$ ) where the serum lithium concentration changed with changes in the total sodium chloride equivalent amount, and we believe that this result demonstrated our ability to maintain the patient's serum lithium concentration within the safe range. When the sodium chloride content in the diet was gradually restricted from normal amounts and the relationship between urinary sodium excretion and lithium clearance was investigated, the results showed that as the urinary sodium excretion decreases, the lithium clearance also decreases. ${ }^{7)}$ Similarly, in the present case, decrease in the sodium intake caused an increase in the re-absorption of sodium ions in the renal tubules, with a resulting relative increase in the re-absorption of lithium ions, decrease in lithium clearance, and change in serum lithium concentration.

Thus, the elevated serum lithium concentration in the present case may have been due to an accelerated decrease in lithium clearance due to a reduction in her total sodium chloride equivalent amount, in addition to a decrease in lithium clearance, caused by moderately reduced renal function. Given that lithium ions behave similar to sodium ions and are relatively greatly impacted by sodium ions, ${ }^{7,8)}$ managing the amount of sodium ions - i.e., sodium chloride in the diet, is important. ${ }^{9)}$ The Dietary Reference Intakes for Japanese people have been revised, and the target daily intake of sodium chloride for individuals aged $\geq 18$ years was decreased from $<9 \mathrm{~g}$ to $<8 \mathrm{~g}$ for men and from $<7.5 \mathrm{~g}$ to $<7 \mathrm{~g}$ for women. However, the guidelines of a number of countries, including Japan, have moved to seek more stringent sodium restrictions, because a sodium chloride intake of $<6 \mathrm{~g} / \mathrm{d}$ is regarded as desirable for preventing or treating hypertension and because the 2013 World Health Organization (WHO) guidelines strongly recommend that adults consume $<5 \mathrm{~g} / \mathrm{d}$ of sodium chloride. In this context, it is possible that decreasing the amount of sodium chloride ingested in the diet in patients who are consuming lithium carbonate may lead to unanticipated changes in the serum lithium concentration. Therefore, careful monitoring of the sodium chloride intake simultaneously with more careful monitoring of serum lithium concentration is required.

Conflict of interest The authors declare no conflict of interest.

\section{REFERENCES}

1) Package insert of LIMAS ${ }^{\circledR}$ tab. 100/tab. 200, Taisho Toyama Pharmaceutical Co., Ltd., 2012.

2) Timmer R. T., Sands J. M., J. Am. Soc. Nephrol., 10, 666-674 (1999).

3) Ebara T., "Lithium Treatment in Psychiatry," Chap. V, ed. by Watanabe S., Furukawa T., Ebara T., Kariya T., Ishiyaku Publishers, Inc., Tokyo, 1990, pp. 203-218.

4) Ministry of Health, Labour and Welfare. "Dietary Reference Intakes for Japanese (2015)"':〈http://www.mhlw.go.jp/file/05Shingikai-10901000-Kenkoukyoku-Soumuka / 
0000083869.pdf $\rangle$, cited 28 August, 2015.

5) Zou J., Li Y., Yan C.-H., Wei F.-F., Zhang L., Wang J.-G., Hypertension, 62, 719-725 (2013).

6) Goto H., Tomita T., Doki S., Nakanishi R., Kojima C., Yoneshima M., Yoshida T., Tanaka K., Kohda Y., Yakugaku Zasshi, 135, 643-
646 (2015).

7) Thomsen K., Schou M., Am. J. Physiol., 215, 823-827 (1968).

8) Thomsen K., Schou M., Pharmacopsychiatry, 32, 83-86 (1999).

9) Sawada Y., Medicine and Drug J., 35, 28962898 (1999). 